\section{IUGS and the State of the Geosciences}

\author{
- Based on a speech delivered at the Opening \\ Ceremony of the 32nd International Geolog- \\ ical Congress in Florence, August 2004
}

After the worst decline in fortune for decades, the geosciences are on the way up again. Yet, how relevant are geoscientists in today's world?

Before satellites began to explore our planet from outer space, solid earth studies were the sole domain of geologists. Then, geophysics and geochemistry developed as separate disciplines. Today these distinctions are becoming less prominent as many interdisciplinary fields continue to develop along the interfaces between classic sub-disciplines, all dealing with System Earth.

The relevance of the geosciences may be expressed through their numbers. An enquiry among geological societies in 13 nations revealed that, on average, geoscientists in developed countries may outnumber their colleagues in the developing countries by 2 to 1 . If these data are representative, planet Earth hosts about 400,000 geoscientists. The relevance of the geosciences to human society may also be expressed in economic terms. A recent study in the UK showed that non-geoscientists estimate our contribution at 5-8\% of Gross Value Added; that is 55-100 billion Euros every year. A similar investigation in the Netherlands showed slightly lower but broadly similar values (3-7\%; Heederik \& Speelman, 2003). These numbers indicate that the information produced by geoscientists can earn for a nation at least 1000 times more than it costs to run a Geological Survey organisation for a year.

Despite the high economic relevance of the geosciences, they have been in decline for several decades. The economic boom and high commodity prices in the 30 years following World War II demanded massive development of geoscientific expertise. The International Geophysical Year (1957-58), innovative space technology, and major geoscientific discoveries such as plate tectonics, further triggered this interest. Research budgets rose - as did the number of students. New organisations (IUGS in 1961, IGCP in 1972) emerged, but such positive developments led to rapid intellectual advances that gave rise to divergence within the geosciences and the growth of separate geoscience organisations.

This picture changed dramatically in the 1980s. Commodity prices plunged and environmental awareness grew. Public awareness of the extractive industries, traditional employers of geoscientists, declined as the attitude of the media became increasingly negative. The geosciences were associated with exploitation of the Earth. Economic recessions and rising unemployment contributed to the negative public perception of geoscience. This was evident during the launching of the International GeosphereBiosphere Programme. Despite the inclusion of 'geosphere' in the title of this major initiative, the geosciences were excluded from this Programme in practical terms.

Despite continuing public interest in dinosaurs, volcanoes and such like phenomena, public and political attention has continued to decline. Geological Survey organisations and the extraction industry were reorganised and their personnel reduced. The geosciences adapted by developing new scientific fields more closely targeted on the environment and society. The negative spiral finally decelerated only when the term 'sustainable development' entered everyday language. In that respect, the World Summit on Sustainable Development in Johannesburg (2002) was a landmark. The blockade on economic development was lifted on condition that development was made environmentally sustainable. Confrontation gave way to cooperation. When the economy boomed again, together with the associated enhancement of demand for natural resources, the curve started to rise. Thus it is that a new spirit of involvement in advancing knowledge and its application to societal needs and problems can now be sensed among geoscientists. New alliances are now creating bridges both within the geosciences and between the geosciences and other sciences, both natural and social.

In parallel with these developments, exciting progress has also been made in geoscientific research. Knowledge has advanced in both amount and resolution with respect to the chronostratigraphic record, climate reconstruction, palaeogeography, and Earth's structure. The Earth is revealing its secrets at an increasing pace. Geoscientists are now able to study the crust in all four dimensions, and so provide material assistance in tackling problems involved in sustainable development.

In line with such developments in the geosciences, the International Union of Geological Sciences (IUGS) has progressively evolved since its formation in 1961. After a period of decline, the Union was reviewed in 1999. This resulted in 32 recommendations designed to improve the organisation in respect of its science, operations and visibility. Implementing these recommendations was the first priority of the new IUGS Executive Committee elected in 2000. A focus on new and more societal relevant science was addressed by the establishment of a Committee on Research Directions, by adding a fifth Working Group (on Groundwater) and so expanding the IGCP, and by successful applications for ICSU Grants. Significant amounts of money were successfully invested in the initiatives on Medical Geology and Environmental Geo-Indicators. Simultaneously, active IUGS Commissions and other bodies in the IUGS family were provided with more money. In summary, more of the IUGS budget was invested in science while administrative costs were kept low.

IUGS also streamlined its operations. Publications were outsourced to the Geological Society of London, so relieving the Union of the burden of running its own publishing operation, while, at the same time, allowing it to focus on its core activity, namely stimulating scientific communication both among geoscientists and between geoscientists and society. The IUGS house journal Episodes further improved its professional and scientific status. Its citation indexfactor has risen by a factor of 5 since 1992 .

The uncovering of institutional 'transparency' or 'visibility' problems by the 1999 review spurred the Union to improve its image and exposure. As its traditional, 40 year old logo (a hammer-pierced globe) was too clearly suggestive of exploitation, a new logo was designed that was more clearly expressive of stewardship and balanced use of Earth resources. Exposure was improved by providing the geoscience communities and others with more up-to-date and attractive publicity materials, including new flyers, posters, brochures, annual reports, and e-bulletins.

The Union's response to the recommendations set out in the 1999 review were published in a booklet, together with a Mid-Term Vision and a 'road map' towards 2011, the year that will witness the Union celebrating its 50th anniversary. By that time, the Union looks forward to much closer cooperation between ICSU's Geo-unions, with a more prominent role in global geoscience research programmes, much better exposure of the role of geoscience in society, and much greater involvement of the developing countries in IUGS activities.

In 2004, tangible partnerships were proclaimed with three of our 'sister' unions in ICSU: the International Union of Geodesy and Geophysics (IUGG), the International Geographical Union (IGU) and the International Union of Soil Scientists (IUSS). In addition, IUGS and the International Geological Congress, which are two entirely separate organisations, have worked hard to forge integration of the two bodies. A first step in this process was realised at the 32 nd IGC when the Councils of the two organisations were merged.

The boldest step so far undertaken to ensure greater public exposure of the geosciences has been the programme leading to the proclamation of an International Year of Planet Earth. Together with UNESCO's Earth Science Division and 11 Founding and 18 Associate Partner organisations, we aim to match the great successes of the International Geophysical Year in 1957/58 and the National Year of the Geosciences in Germany in 2002. The Year's logo (kindly provided by the Organising Committee of the German Year) highlights the position of the geosphere in System Earth. The International 
Year seeks UN proclamation because potential sponsors in the private sector request substantial political support as a pre-requisite for successful large-scale fund raising. The worldwide support for this endeavour by the geoscience community demonstrates that the Union has taken the right initiative in a timely way.

The sub-title of the International Year is 'Geoscience for Society'. These few but wellchosen words will serve as a constant reminder that the Year's overriding aim is to demonstrate to society at large the great potential of our science in humanity's search for a safer, healthier and wealthier global society. Many people around the world suffer daily because of failure to apply readily available geoscience knowledge and techniques in the planning and management processes. It is for this reason that the International Year of Planet Earth will focus on science and on outreach. The outreach plan will mobilize the enthusiasm of the public, students, school children and politicians around the world. Successful implementation of the International Year of Planet Earth should raise the level of political awareness of the benefits of our science to society; it should also indicate the need for much more widespread application of this so far underexploited knowledge to the business of dayto-day decision-making. As demonstrated in Germany, the Year should stimulate student registrations in Geosciences, and eventually raise budgets for geoscientific research.

One operational aspect of the International Year of Planet Earth that sets it apart from many earlier proclaimed UN years is worthy of particular note. All 10 of the Years broad scientific Themes will operate in 'bottom-up' mode, and thus be open to project proposal submissions from the global community. In this way, the International Year will continue and, at the same time, develop the principle underpinning the 33 years of success so far enjoyed by the International Geoscience Programme (IGCP).

Finally, it is important to recognise that the International Year of Planet Earth will, in fact, be a triennium (2007-2009), centred upon the UN-proclaimed year (2008). A three-year time span is the minimum needed to realise the rather ambitious scientific and outreach programmes. This endeavour will be successful only if implemented on local as well as national levels. We therefore encourage geoscientific communities to create both national and local committees and to develop plans for organising exciting events and activities.

The ultimate mark of success will be the number and stature of the local, national and international achievements within 12 months of the end-date of its triennium, and the indicators of impact levels among both public and governments. The success of the International Year of Planet Earth can be confidently expected to boost further the emergence of the geosciences from the shadows of the past few decades.

\section{Eduardo F.J.de Mulder}

Past-President, IUGS

Chair, Management Team

International Year of Planet Earth 